\title{
Consideraç̧̃es acerca do ensino de Ciências nos anos iniciais do Ensino Fundamental
}

\section{Considerations about Science teaching in the first years of elementary school}

\author{
${ }^{1}$ Elizabeth Macedo Fagundes \\ ${ }^{1}$ Nilcéia Aparecida Maciel Pinheiro
}

\section{RESUMO:}

O presente artigo objetiva investigar como ocorre o ensino de Ciências nos anos iniciais do Ensino Fundamental, contemplando com maior profundidade a contribuição dos temas geradores, a fim de que a prática docente consiga mobilizar a participação ativa dos educandos na construção do saber. A investigação e a intervenção foram realizadas pela pesquisadora em sala de aula, contando com a participação dos alunos do $3^{\circ}$ ano do ensino fundamental, numa escola da Rede Municipal de Guarapuava. Para tanto, fora utilizado o método de pesquisa qualitativa, de cunho interpretativo e de finalidade aplicada. No decorrer do desenvolvimento das atividades, percebeu-se a motivação dos alunos a cada aula, demonstrando maior envolvimento e interesse para aprender.

Palavas-chave: Ensino de Ciências. Tema gerador. Prática docente.

\section{ABSTRACT:}

This article aims to investigate how science teaching occurs in the firts years of elementary school, covering with greater depth the contribution of generative themes, so that the teaching can mobilize the active participation of learners in the constriction of knowledge. Research and intervention were conducted by the researcher in the classroom, couting with the participation of the $3^{\circ}$ year of elementary school students of a f Municipal School in Guarapuava. For that, a qualitative research was used with interpretive nature and applied purpose. During the development of the activities, the motivation of the students to each class, demonstrating greater involvement and interest to learn, were observed.

Key words: Sciente Teaching; Generator Theme; Practice. 


\section{INTRODUÇÃO}

A Lei Federal no 9.394/1996 (Lei de Diretrizes e Bases da Educação Nacional - LDBEN) introduziu no Brasil, uma nova percepção acerca da atuação do docente no Ensino Fundamental, por instituir como principal objetivo da educação - o pleno desenvolvimento do aluno. Dessa forma, o pleno desenvolvimento contempla, além da dimensão intelectual, a dimensão social, cultural, política, científica, dentre outras, revelando o reconhecimento da educação escolar como fator relevante na formação humana.

A partir dessa lei, foram elaborados os Parâmetros Curriculares Nacionais - PCN, que instituíram referenciais para a prática docente, visando a uma educação escolar que concilia os conhecimentos científicos aos saberes sociais, incluindo, nesse contexto, os saberes assimilados pelos educandos. Em virtude desses referenciais, da LDB e dos PCN, a prática pedagógica foi reavaliada, e, no caso específico do ensino de Ciências, a prática docente busca propiciar uma aprendizagem mais contextualizada.

Isso decorre do fato de se estabelecer uma relação entre os conteúdos científicos e os temas sociais relevantes, com o objetivo de proporcionar uma percepção ampla acerca da Ciência e de sua importância na sociedade, a fim de perceber a repercussão do seu uso nas mais diversas atividades. Para Freire (1999), um suporte significativo para o desenvolvimento da prática de ensino em Ciências reside na definição dos chamados temas geradores, que instigam o docente a estimular o aprendizado dos conteúdos da disciplina, a partir da análise de uma situação concreta que seja de conhecimento dos educandos.

Nessa perspectiva, o presente artigo tem por objetivo analisar o ensino de Ciências nos anos iniciais do Ensino Fundamental, abordando os conteúdos a partir dos temas geradores, para que a prática docente consiga mobilizar a participação ativa dos educandos na construção do saber.

\section{O ENSINO DE CIÊNCIAS NOS ANOS INICIAIS NO ENSINO FUNDAMENTAL: PERSPECTIVAS ATUAIS}

Anterior a Lei de Diretrizes e Bases da Educação Nacional de 1996, o ensino de Ciências, nos anos iniciais do Ensino Fundamental, assim como das demais disciplinas, era pautado num processo restritivo, ou seja, visava apenas ao repasse conteúdo, evitando o questionamento, a reflexão e o debate acerca dos conteúdos apresentados. Conforme Nigro e Campos (2009, p. 05), "isso acontecia devido à visão de ciência e tecnologia que se tinha na época, quando a ciência era tida como verdade absoluta”. Assim, o objetivo para o ensino das Ciências era ensinar o que estava escrito nos livros e valorizar a ciência como algo que possibilitava ao ser humano dominar a natureza e, até mesmo, explorar o Universo.

Atualmente, não se aceita mais o conhecimento científico como absoluto nem o "ensino" a partir da memorização, sendo necessário levar em conta que hoje, os alunos têm mais acesso à informação, seja por meio de jornais, revistas, ou ainda, da internet, dentre outros aportes tecnológicos, que propiciam a elaboração de saberes e de percepções particularizadas, que podem contribuir para a formação dos alunos. Pensando assim, os Parâmetros Curriculares Nacionais - PCN cujas diretrizes são pautadas nas disposições constantes na LDBEN DE 1996 alertam para o fato de que

é papel da escola e dos professores estimular os alunos a perguntarem e a buscarem respostas sobre a vida humana, sobre os ambientes e recursos tecnológicos que fazem parte do seu cotidiano ou que estejam distantes no tempo e no espaço. (BRASIL 1997, p. 61)

Autores como (Carvalho et. all. 2007) afirmam que, se a criança tiver os primeiros contatos com a ciência de forma agradável, há possibilidade de que nos anos seguintes, possa melhorar seu aprendizado. Caso contrário, se o ensino exigir memorização, possivelmente os alunos terão aversão pelas ciências. Diante disso, os PCN 
(BRASIL 1997) apontam que os conteúdos da aprendizagem não são somente os de natureza conceitual, mas também, os procedimentais e atitudinais.

A saber, os chamados Conteúdos Conceituais da área das Ciências Naturais remetem aos conhecimentos construídos pela humanidade ao longo da história, conforme os PCN,

são conhecimentos desenvolvidos pelas diferentes ciências e aqueles relacionados às tecnologias, é um primeiro referencial para os conteúdos do aprendizado. Estão organizados em teorias científicas, ou em conhecimentos tecnológicos, que não são definidos, mas se transformam continuamente. [...] A compreensão integrada dos fenômenos naturais, uma perspectiva interdisciplinar, depende do estabelecimento de vínculos conceituais entre as diferentes ciências. Os conceitos de energia, matéria, espaço, tempo, transformação, sistema, equilíbrio, variação, ciclo, fluxo, relação, interação e vida estão presentes em diferentes campos e ciências, com significados particulares ou comuns, mas sempre contribuindo para conceituações gerais. (BRASIL 1997, p. 41)

Nessa abordagem, para que haja a compreensão dos alunos quanto à relação dos fenômenos naturais com o conhecimento tecnológico, necessário se faz que o professor tenha isso em mente, no momento da elaboração do planejamento das aulas. Ao planejar as atividades a serem desenvolvidas, é preciso pontuar os objetivos que pretende atingir, indicar os conteúdos que serão desenvolvidos, selecionar os procedimentos que utilizará e prever quais instrumentos empregará para avaliar os alunos. Para Soares (2009, p. 06), “o docente precisa ter um planejamento organizado em torno de suas competências, porque assim facilitará em sua prática a percepção dos problemas que confronta aos alunos e a partir deles procurar métodos para controlar o processo de aprendizagem”.

Conforme os PCN (BRASIL 1997), além dos conteúdos conceituais outro importante referencial para a aprendizagem nas ciências naturais são os conceitos do senso comum acerca da natureza e da tecnologia. Estes, são conhecimentos que os alunos trazem para a escola, que interferem no aprendizado científico e que fazem ter diferentes interpretações, modos de perguntar, de selecionar e de elaborar o conhecimento.

Os procedimentos científicos, por sua vez, são definidos como conteúdos procedimentais, ou seja, conteúdos,

que se referem ao "saber fazer”, ou seja, envolvem o ensino- aprendizagem de ações específicas. [...] os conteúdos procedimentais a serem ensinados-aprendidos em Ciências não são aqueles unicamente relacionados à aprendizagem do método experimental ou do método científico, mas que incluem métodos para o trabalho de investigação, técnicas gerais de estudo, estratégias que possibilitem e facilitem a comunicação, estabelecimento de relações, destrezas manuais, etc. (NIGRO; CAMPOS, 2009, p. 23)

Podemos dizer, então que a dificuldade encontrada pelo professor no ensino de Ciências ocorre pelo fato de não explicitar os conteúdos procedimentais que são os objetivos do processo de ensino-aprendizagem. Para tanto, é preciso "[...] considerar que, aprender conteúdos relacionados ao saber fazer, não é o suficiente falar sobre como se faz; é necessário fazer de fato, quer dizer, para aprender procedimentos devem-se realizar ações” (NIGRO; CAMPOS 2009, p. 25). Nesse sentido, os alunos são estimulados a refletir sobre o porquê de realizar determinadas atividades, ou seja, atribuindo sentido ao que estão aprendendo.

Nigro e Campos (2009) esclarecem ainda, que a aprendizagem de conteúdos conceituais, bem como a de conteúdos procedimentais, não tem um término definido, mas se constituem num processo gradativo de aprendizagem. Além disso, certas estratégias de ensino podem ser adequadas para desenvolver um trabalho simultâneo com os dois tipos de conteúdos, além dos atitudinais.

Sobre os Conteúdos Atitudinais, Nigro e Campos (2009) afirmam que: 
Os conteúdos atitudinais não se referem exclusivamente a comportamentos a serem manifestados pelos estudantes. Eles se referem, de forma geral, ao sentimento ou ao valor que os alunos atribuem a determinados fatos, normas, regras, comportamentos ou atitudes. Alguns conteúdos atitudinais podem ser trabalhados em todas as disciplinas. (ibid., p.32)

Desse modo, ao partir dos conteúdos atitudinais é possível favorecer um trabalho de cooperação, respeitando as ideias e conhecimento de cada um, valorizando a curiosidade sobre os fenômenos naturais. Porém, há conteúdos atitudinais que se referem exclusivamente à área de Ciências, nesse sentido,

[...] a) atitudes dos alunos para com a ciência; essas atitudes se referem ao posicionamento dos alunos em relação aos fatos, conceitos e métodos caracteristicamente científicos, assim como aos profissionais que fazem ciência; b) atitudes científicas; são aquelas relacionadas especificamente à predisposição dos alunos a uma conduta ou uma maneira de ser, supostamente científica. (NIGRO; CAMPOS, 2009, p.33)

O processo de ensino-aprendizagem de conteúdos, de atitudes científicas, de atitudes em relação à ciência e a outros conteúdos atitudinais, conforme Nigro e Campos (2009), dependem muito das atitudes do professor, visto que o professor serve de modelo ao aluno, este que observa e analisa como age o professor. Assim, aspectos como relações afetivas e pessoais estabelecidas durante a aprendizagem e as maneiras pelas quais as atividades são conduzidas têm grande interferência no ensino-aprendizagem das Ciências Naturais.

Por fim, dado que o ensino das Ciências obrigatoriamente envolve atividades práticas, observa-se que o ensino fundamenta-se na imprescindível ação dos alunos no processo, visão que segundo Carvalho et. all. (2007), é possível ir além da mera ação ou atividade de manipulação e observação, mas, concomitantemente, envolvendo reflexão, discussões, ponderações e explicações.

\section{TEMA GERADOR DE ENSINO}

Em muitos casos, não somente na disciplina de Ciências, o professor limita-se ao uso do livro didático e à apresentação de conceitos elaborados sistematicamente, sem aplicá-lo à realidade dos alunos. Desse modo, o ensino torna-se mecânico e tradicional, dificultando a real aprendizagem dos educandos. Por essa razão, ensinar a partir da contextualização do ambiente em que a criança está inserida é uma das formas para enfrentar a problemática da não-aprendizagem e de amenizar as dificuldades encontradas no ensino dos conteúdos de Ciências. Nesse sentido, um dos recursos metodológicos que pode ser utilizado pelos professores, é trabalhar com os chamados temas geradores de Freire (2005).

Nessa perspectiva, Gadotti (2006) explica que Freire desenvolveu uma estratégia por investigação temática voltada à alfabetização de adultos. Sendo assim, todo o processo de ensino era baseado em temas e deles eram retirados os conteúdos escolares necessários ao aprendizado do educando. Inicialmente, conforme o autor, o método passa por três etapas distintas que são: Etapa da investigação, Etapa da sistematização e a etapa da problematização.

Quanto a isso, Delizoicov, Angotti e Pernambuco (2002) afirmam que:

Os temas geradores foram idealizados como um objeto de estudo que compreende o fazer e o pensar, o agir e o refletir, a teoria e a prática, pressupondo um estudo da realidade em que emerge uma rede de relações entre situações significativas individual, social e holística, assim como uma rede de relações que orienta a discussão, interpretação e representação dessa realidade. (ibid., p. 65) 
Desse modo, para que a educação contribua de alguma forma para a transformação do espaço em que estamos inseridos, os temas geradores são elos que, articuladamente, vão promovendo o estudo da realidade local, concomitantemente com a realidade regional, nacional e internacional. Nesse contexto, a prática de estudar a partir de onde estamos inseridos, permite que possamos desafiar e sermos desafiados. Nos PCN, isso está dito nos seguintes termos: “[...] é imprescindível mostrar às crianças a ciência como um conhecimento que colabora para a compreensão do mundo e suas transformações, para reconhecer o homem como parte do universo e como indivíduo" (BRASIL, 1997, p. 25).

Para Delizoicov, Angotti e Pernambuco (2002), os temas geradores têm como princípios básicos:

uma visão de totalidade e abrangência da realidade; a ruptura com o conhecimento no nível do senso comum; adotar o diálogo como sua essência; exigir do educador uma postura de crítica, de problematização constante, de distanciamento, de estar na ação, e de se observar e se criticar nessa ação; apontar para participação, discutindo no coletivo e exigindo disponibilidade dos educadores. (ibid., p.166)

Os temas geradores, seguindo a concepção de Freire (2005), houve a transposição dos pressupostos para o ensino de Ciências por Delizoicov e Angotti (2000) que são: estudo da realidade - ER; organização do conhecimento - OC; e aplicação do conhecimento - AP, sendo todas as etapas baseadas no caráter dialógico estabelecido entre professor, aluno e conteúdo. Para Delizoicov, Angotti e Pernambuco (2002),

O caráter dialógico, com a qualidade de tradutor, deve ser uma das características fundamentais do
modelo didático-pedagógico, cujo eixo estruturante é a problematização dos conhecimentos. Pro-
blematiza-se, de um lado, o conhecimento sobre as situações significativas que vai sendo explicita-
do pelos alunos. De outro, identificam-se e formulam-se adequadamente os problemas que levam à
consciência e à necessidade de introduzir, abordar e apropriar conhecimentos científicos. Daí decorre
o diálogo entre conhecimentos, com consequente possibilidade de estabelecer uma dialogicidade tra-
dutora no processo de ensino/aprendizagem das Ciências. (ibid., p. 197)

Esse caráter dialógico tradutor, que os autores apontam, é apresentado no sentido de que o professor obtenha o conhecimento do senso comum que os alunos possuem, para, a partir desse conhecimento, aguçá-los e propiciar-lhes um distanciamento crítico, ao se defrontarem com o conhecimento científico. Nesse aspecto, o professor poderá estabelecer dinâmicas em sala de aula, caracterizadas como momentos pedagógicos, momentos que podem ser distinguidos em três funções específicas e diferenciadas entre si, conforme foram mencionadas anteriormente.

O primeiro momento, o Estudo da Realidade, também chamado Problematização Inicial, de acordo com Delizoicov, Angotti (2000) é o momento de reflexão e discussões iniciais sobre as questões sugeridas pelos alunos, uma vez que parte da análise de situações reais próximas ao universo social do educando. Para que isso ocorra, o diálogo com os alunos é fundamental, para que o professor tenha condições de detectar as percepções que estes cultivam em relação à situação analisada, podendo avaliar melhor sua utilização no ensino de Ciências. Cabe ao professor explorar a oralidade de seus alunos, fazendo um resumo do que foi debatido, pois possivelmente haverá diversas opiniões. Os autores ainda alertam que "não se pretende que os alunos "adivinhem" o que a ciência já sabe sobre o assunto em questão; pretende-se, sim, apreender a visão dos alunos sobre o assunto” (ibid., p.118).

Desse modo, na problematização inicial são apresentadas as

[...] situações reais que os alunos conhecem e presenciam e que estão envolvidas nos temas, embora também exijam, para interpretá-las, a introdução dos conhecimentos contidos nas teorias científicas. Organiza-se esse momento de tal modo que os alunos sejam desafiados a expor o que estão pensando sobre as situações. Inicialmente, a descrição feita prevalece para o professor poder ir conhecendo o que pensam. A meta é problematizar o conhecimento que os alunos vão expondo, de modo geral, com base em poucas questões propostas relativas ao tema e as situações significativas, questões inicialmente discutidas num pequeno grupo, para, em seguida, serem exploradas as posições dos vários grupos com toda a classe, no grande grupo. (ibid., p.120) 
Nessa concepção, a função do professor concentra-se como mediador nos questionamentos, fomentando discussões, levantando dúvidas sobre o tema abordado, concomitantemente às explicações pertinentes ao assunto. Nesse momento, cabe ao professor instigar para que os alunos sintam a necessidade da aquisição de outros conhecimentos que ainda não detêm, ou seja, procura-se configurar a situação em discussão como um problema que precisa ser enfrentado. Cabe ressaltar ainda, que a problematização é empregada no estudo da realidade em virtude de, na concepção de Delizoicoy e Angotti (2000, p. 54), ?][...] permitir que o aluno sinta necessidade de adquirir outros conhecimentos que ainda não detém; ou seja, coloca-se um problema para ser resolvido??

Ao ensinar a partir dos temas geradores, o educador proporciona um conhecimento contextualizado com a realidade local, relacionando com um contexto mais amplo. Entende-se, assim, que o conhecimento não está pronto e acabado, e que a escola, a sala de aula, é um importante espaço para que o aluno possa expor seu modo de interpretar o mundo e não apenas reproduzir mecanicamente os conteúdos.

Na sequência, a Organização do Conhecimento é o segundo momento pedagógico, quando se ensina a partir dos temas geradores. Para que o professor viabilize a aprendizagem contextualizada, torna-se importante incorporar conteúdos que se relacionam às ideias e aos conceitos que os alunos já possuem, ou seja, é fundamental considerar, explorar e ativar os conhecimentos prévios e as experiências dos alunos.

A interação com os alunos, no estudo da realidade, que é o segundo momento pedagógico, Delizoicov, Angotti e Pernambuco (2002) apregoam que:

os conhecimentos selecionados como necessários para a compreensão dos temas e da problematização inicial são sistematicamente estudados neste momento sob a orientação do professor. As mais variadas atividades são empregadas, de modo que o professor possa desenvolver a conceituação identificada como fundamental para uma compreensão científica das situações problematizadas. É neste momento que a resolução de problemas e exercícios, tais como os propostos em livros didáticos, pode desempenhar sua função formativa na apropriação de conhecimentos específicos. (ibid., p.201)

Nesse momento da organização do conhecimento é fundamental a mediação do professor, especificamente para que o aluno se sinta instigado a buscar novos conhecimentos, a fim de apontar as possíveis soluções para o problema observado.

Para Freire (2005), desenvolver um trabalho partindo do contexto e que os alunos estão inseridos, é respeitar os diferentes níveis de conhecimento que o aluno traz para a escola, aperfeiçoando e organizando-os de modo significativo. Esse tipo de trabalho, tanto na disciplina de Ciências quanto em outras, faz com que os alunos sintam-se estimulados a aprender, uma vez que percebem o elo existente entre o conhecimento científico e o que eles vivenciam. Nesse sentido, a principal preocupação da Educação é o desenvolvimento de uma concepção problematizadora e libertadora de educação proposta por Freire (2005), que se fundamenta precisamente na relação dialógica/dialética entre educador e educando, em que ambos aprendem juntos.

Sobre a aplicação do conhecimento, terceiro momento pedagógico, Delizoicov, Angotti e Pernambuco (2002) afirmam que essa etapa

destina-se, sobretudo, a abordar sistematicamente o conhecimento que vem sendo incorporado pelo aluno, para analisar e interpretar tanto as situações iniciais que determinam seu estudo como outras situações que, embora não estejam diretamente ligadas ao motivo inicial, podem se compreendidas pelo mesmo conhecimento. Do mesmo modo que no momento anterior, as mais diversas atividades devem ser envolvidas, buscando a generalização da conceituação que já foi abordada e até mesmo formulando os chamados problemas abertos. (ibid., p. 202) 
Nessa abordagem, o suporte teórico fornecido pela ciência, e que está em pauta, é o uso articulado da estrutura do conhecimento científico com as situações significativas, envolvidas nos temas abordados. Na aplicação dos conhecimentos, os alunos podem compreender de modo significativo os saberes elaborados desde o início do processo de ensino, fato decorrente do nível de interação que o educando teve com o conhecimento científico abordado a partir dos temas geradores.

Assim, ensinar a partir de temas centrados na realidade, enriquecidos com leituras complementares sobre as necessidades sociais, do momento histórico em que os alunos estão inseridos, possivelmente, proporcionará aos alunos o desenvolvimento da participação mais ativa na comunidade em que vivem. Desse modo, é imprescindível que a escola e professores se encontrem produzindo trabalhos articulados, afinados ao interesse da população e às exigências da comunidade, buscando a real participação de todos na solução dos problemas da sociedade. Nesse contexto, Lück (1994) afirma que, para o desenvolvimento das atividades de maneira interdisciplinar, é necessário o envolvimento e o apoio de toda a comunidade escolar, para que se estabeleça uma perspectiva comum de trabalho, envolvendo todos em torno de objetivos comuns explicitados pela comunidade escolar e continuamente revistos, atualizados e alterados segundo os interesses emergentes.

Nesse sentido, o ensino a partir de temas geradores em sala de aula possibilita aos alunos não só a busca de informações, mas também a oportunidade de adquirir habilidades, a fim de mudar comportamentos, de ver os acontecimentos de maneira diferente, de construir seu conhecimento de forma prazerosa e transformadora, utilizando-se da integração, da cooperação e da criatividade, tendo em vista a construção do cidadão competente e produtivo. Sob essa perspectiva, Freire (2005) nos mostra que a busca por um ensino significativo acontece de maneira problematizadora e dialógica, o que também possibilita a reflexão sobre a realidade. Assim, além de possibilitar a apreensão do tema gerador e do planejamento, insere ou começa a inserir os alunos numa forma crítica de pensarem seu mundo.

Para a realização de atividades com os temas geradores, é necessário primeiramente explicar aos alunos como serão desenvolvidas as atividades, a fim de contextualizá-los com relação as atividades. Conforme Gasparin (2005), mesmo que inicialmente, eles não demonstrem clareza sobre o que é para ser feito, aos poucos se vai dialogando sobre o tema a ser trabalhado e firmando um entendimento mais preciso. Assim, a tarefa do professor é mediar o processo educativo desenvolvido na escola, é articular ensino e realidade, enfim, fazer acontecer um elo significativo entre as disciplinas.

\section{METODOLOGIA}

Nossa intenção foi a de utilizar temas do cotidiano como referencial metodológico nos anos iniciais do ensino fundamental, de maneira que pudessem ser estabelecidas juntamente com os alunos, as relações existentes entre as Ciências Naturais e a realidade. A escolha do tema da alimentação saudável com enfoque na alimentação escolar ocorreu pelo fato de essa problemática estar presente no cotidiano dos alunos, além de oferecer a possibilidade de se trabalharem diferentes conhecimentos previstos na grade curricular do terceiro ano do ensino fundamental.

Assim, foram aplicadas várias atividades aos alunos, de maneira a permitir que tais relações fossem estabelecidas por meio do tema “Alimentação Escolar”. Nesse sentido, nosso estudo seguiu os caminhos da pesquisa qualitativa, pois nossa intenção foi a de obter dados que pudessem ser descritos mediante o contato direto da pesquisadora com o objeto estudado. Além disso, de acordo com Neves (1996, p. 1), a pesquisa qualitativa ? [...] tem por objetivo traduzir e expressar o sentido dos fenômenos do mundo social. Trata-se de reduzir a distância entre indicador e indicado, entre teoria e dados, entre conexão e ação?. As atividades propostas nesta pesquisa foram aplicadas em cinco encontros, das $13 \mathrm{~h}$ às $17 \mathrm{~h}$, nos meses de maio, junho e agosto de 2012. Foram direcionadas para alunos com idades entre oito e doze anos, de uma classe composta por 
28 alunos matriculados no terceiro ano do ensino fundamental de nove anos, em uma Escola da Rede Municipal de Ensino da cidade de Guarapuava - Paraná, Brasil.

A coleta e análise dos dados ocorreram por meio da pesquisa qualitativa de cunho interpretativo, sendo de finalidade aplicada

\section{RESULTADOS E DISCUSSÕES}

Com o intuito de aprimorar a prática docente, buscando temas do cotidiano dos alunos, um fato nos chamou a atenção: sempre que entrávamos em sala de aula, os alunos perguntavam: "Professora o que tem hoje de lanche?" Porém, observou-se que em alguns dias, não sobrava lanche e em outros havia desperdícios de alimentos.

Partindo dessa constatação, em uma das aulas utilizamos uma música que falava sobre os alimentos, sendo entregue uma cópia da letra para cada aluno, como mostra o QUADRO 1, a seguir.

\section{Quadro 1: Os Bons Alimentos}

\begin{tabular}{|l|l|}
\hline LETRA: OS BONS ALIMENTOS & $\begin{array}{l}3 \text { - Para ter força } \\
\text { Leite vou beber, leite vou beber } \\
\text { Carne, peixe e ovos } \\
\text { Um pouco vou comer } \\
\text { 1- Os bons alimentos }\end{array}$ \\
$\begin{array}{l}\text { Eu devo comer, eu devo comer } \\
\text { Para ter saúde }\end{array}$ & Um pouco vou comer \\
E poder crescer & 4 - Façam como eu \\
Para ter saúde & Prestem atenção, prestem atenção \\
E poder crescer & Pão e iogurte \\
& Energia dão \\
2- Doces só nas festas & Pão e iogurte \\
E sumos também, e sumos também & Energia dão \\
Fruta e legumes & \\
É que fazem bem & 5 - E a amiga sopa \\
Fruta e legumes & Nunca esquecer! Nunca esquecer! \\
É que fazem bem & Tem vitaminas \\
& Doenças não vou ter \\
& Tem vitaminas \\
& Doenças não vou ter \\
\hline
\end{tabular}

Fonte: http://www.vagalumeletras.net/mp3/bons-alimentos-todos-os-patinhos.html

Iniciamos a atividade com a leitura da letra e na sequência, cantamos a música. Ao finalizá-la, deixamos que os alunos pudessem discutir um pouco sobre o significado da letra da música, o que trouxe a tona a importância dos alimentos, a energia que cada um proporciona, bem como as vitaminas necessárias para nosso organismo. Aproveitamos esse momento, para inserir na discussão a questão da merenda escolar, oferecida pela escola.

Como no planejamento anual da disciplina de Ciências do terceiro ano, o tema principal é "ser humano e saúde”, aproveitamos para desenvolver atividades que pudessem abordar os princípios de uma alimentação saudável. Assim, foi possível aliar o assunto a uma metodologia que proporcionasse o maior envolvimento dos alunos nas atividades. Para tanto, adotou-se o trabalho por meio de temas geradores como estratégia para o ensino dos conteúdos de ciências. 
Tal abordagem metodológica fora escolhida, pelo fato de eles proporcionam uma visão da totalidade e abrangência da realidade, além de romper com o conhecimento dado apenas de maneira informal ou sistematizada, bem como trazer para dentro da sala de aula o diálogo e a participação direta dos alunos.

Dessa maneira, na continuidade das atividades, procuramos junto com os alunos, compreender um pouco mais sobre os alimentos utilizados na alimentação da escola, realizando uma pesquisa sobre de onde vêm os alimentos.

Com essa atividade (FIGURA 1), percebeu-se a curiosidade das crianças sobre a alimentação escolar. Surgiam comentários entre os alunos, como: “- Será que hoje vai ter alimentos naturais ou industrializados? ” Outro perguntava: "De qual alimento você mais gosta? De quais alimentos você não gosta? - Os alimentos vêm do mercado? Vamos perguntar para a 'tia da cozinha'? Diante desses questionamentos, a professora sugeriu que seria importante conversar com a merendeira da escola.

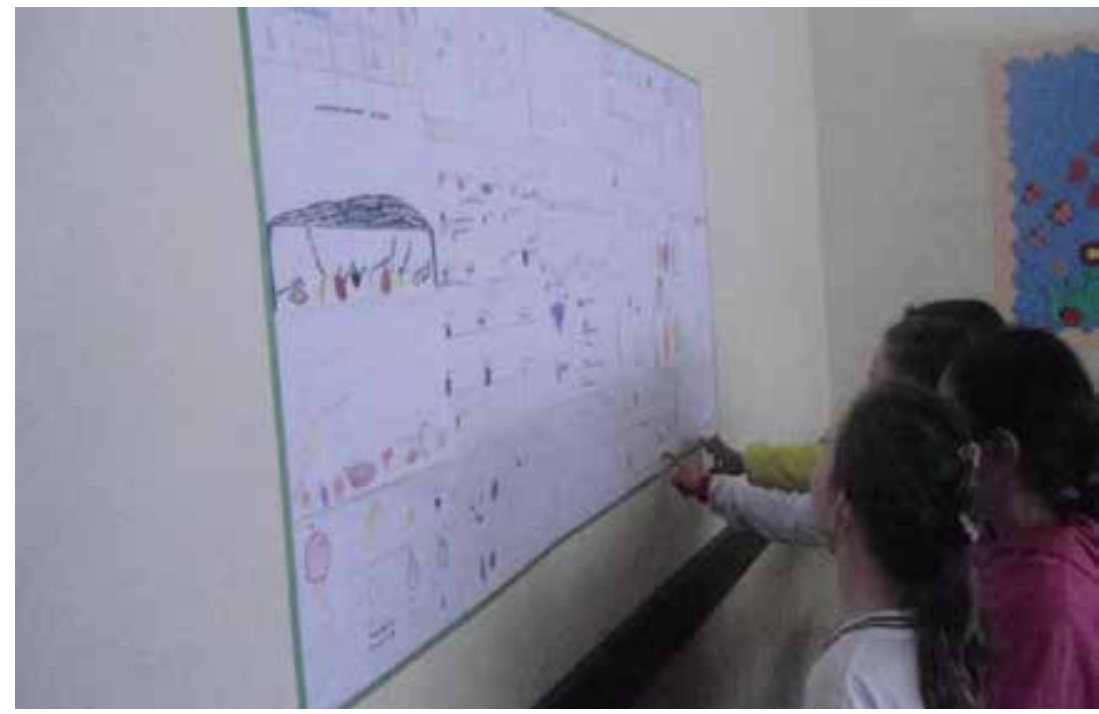

Figura 1-Apresentação dos alimentos naturais Fonte: Arquivo pessoal da autora

Assim, com a intenção de saber da onde vêm os alimentos, que são servidos na merenda escolar, fora organizado um roteiro com perguntas, para melhor conversar com a merendeira, conforme QUADRO 2.

\section{Quadro 2: Roteiro - Entrevista Com A Merendeira da Escola}

Da onde vem os alimentos para a Merenda?

Como são armazenados os alimentos?

São utilizados mais alimentos naturais ou industrializados?

Como é preparada o nosso alimento?

Porque vocês usam “essa touca” na cabeça?

O que é feito dos alimentos que sobram?

Por que nem sempre a merenda está gostosa?

E por que quando está gostosa nunca tem repetição? 
A presença da merendeira em sala de aula motivou os alunos à busca de mais informações sobre a merenda escolar, além das perguntas selecionadas previamente em sala. A entrevista com a merendeira foi a marca da organização do conhecimento, visto que por meio dela, foi proporcionado o acesso a informações relevantes para a compreensão acerca da merenda presente na escola.

Isso ocorreu com tal naturalidade, que a merendeira percebeu o interesse dos alunos e relatou que a cozinha da escola nem sempre foi como está hoje, que atualmente dispõe de fogão industrial, de geladeira e de freezer, mas que a escola funcionava em outro local, num prédio pequeno, de madeira, e a cozinha era precária. Dessa maneira outros questionamentos fora surgindo: O que é precária? Um aluno perguntou. Logo um amiguinho respondeu: - Que não tem quase nada!

Seguindo com o relato, a merendeira informou que onde se encontra a escola atualmente, era um campo e tinha um "banhado", mas como o bairro foi crescendo, houve a necessidade de construir uma escola maior. E os alunos continuaram: E uma cozinha maior. - Disse uma aluna. - Com panelas grandes.

Foi perceptível o interesse dos alunos sobre o assunto, pois a explanação da merendeira foi marcada por muitos momentos de interrupções devido às perguntas ou aos comentários dos alunos. Diante disso, o professor, sem abandonar os conhecimentos sistematizados da disciplina ou da exposição verbal dos conteúdos, assume a função de mediador, considerando que o aluno precisa assumir uma postura ativa no processo de ensino-aprendizagem, para que conseguisse desenvolver sua capacidade cognitiva, suas habilidades e competências, tendo noção do valor do seu aprendizado perante a sociedade.

As competências puderam ser verificadas no diálogo com a merendeira, ao questionarem como a merenda escolar chega até a escola e como se armazenam os alimentos. Esses questionamentos favorecem o aprendizado colocando em prática os conceitos, os procedimentos e as atitudes desenvolvidos no processo de ensino-aprendizagem, conforme a FIGURA 2 a seguir:

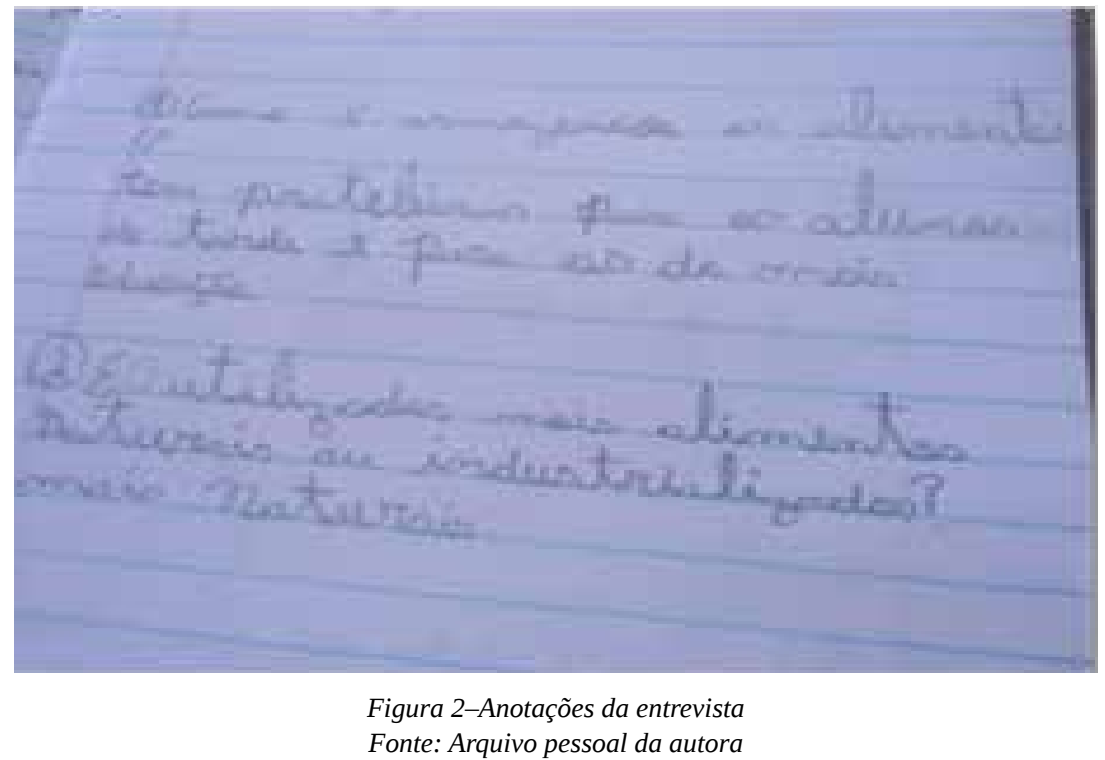

Após a entrevista com a merendeira, de posse das respostas obtidas, realizaram-se as seguintes atividades:

- Com a utilização de uma balança, foram pesados os alimentos que sobraram nos pratos do terceiro ano;

- Organizou-se um painel comparativo com a quantidade de alimentos utilizados para a preparação dos alimentos e a quantidade das sobras nos pratos;

- Os alunos fizeram um gráfico, da quantidade das sobras dos alimentos nos pratos; 
- $\quad$ Socialização das atividades desenvolvidas.

No desenvolvimento das atividades, os alunos mostraram habilidades ao utilizarem instrumentos como à balança e ao fazerem o comparativo dos alimentos que foi utilizado para a preparação da merenda e o que sobrou, na sistematização das informações relevantes para a compreensão da situação-problema - sobra de alimentos em quilos - conforme a FIGURA 3 abaixo:

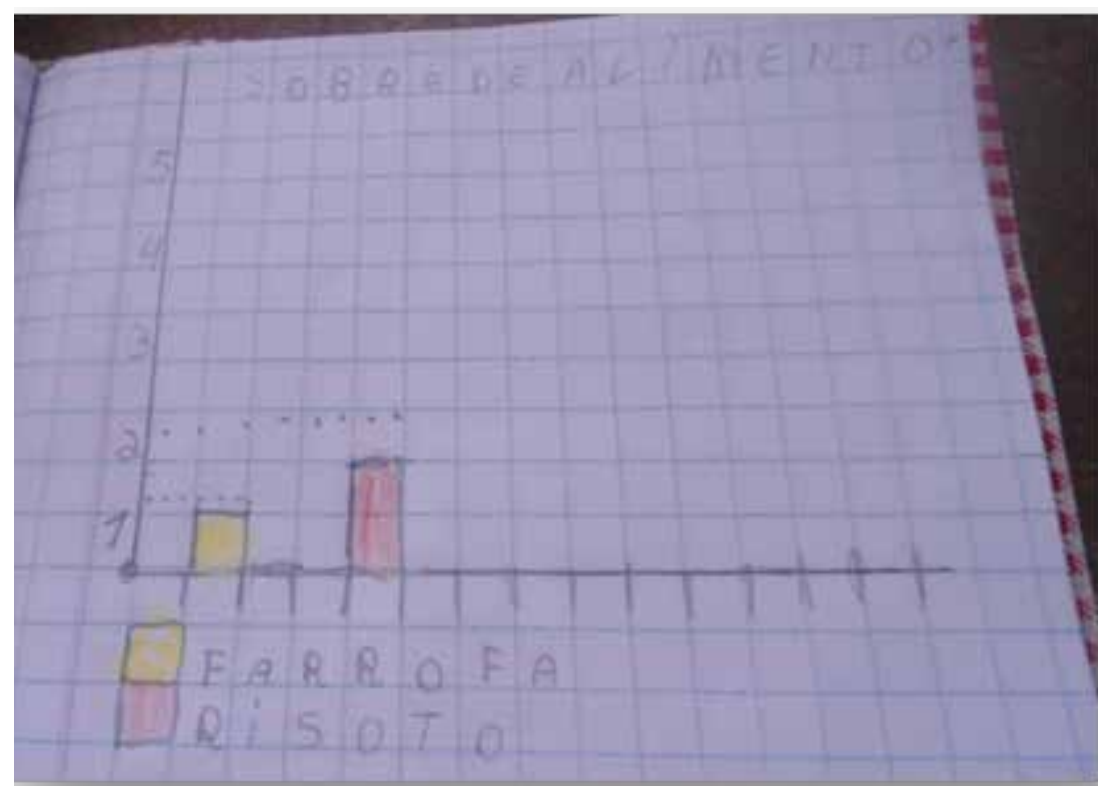

Figura 3 - Gráfico dos alunos

Fonte: Arquivo pessoal da autora

O gráfico mostra a sobra de três quilos de alimentos, apenas numa tarde, na turma do terceiro ano, o que chamou a atenção de todos, uma vez que desconheciam o desperdício de tantos alimentos. Ao desenvolver essas atividades, mais do que informações, houve a contribuição para que o aluno desenvolvesse habilidades e competências que lhe permitiram trabalhar questões como: selecionar, criticar, comparar, elaborar novos conceitos a partir dos que se tem.

Na realização dessa atividade contemplou-se a aprendizagem dos conteúdos conceituais, como salienta Coll et. all. (1998),

\begin{abstract}
o que importa é que os alunos possam construir significados e atribuir sentido àquilo que aprendem. Somente na medida em que se produz este processo de construção de significados e de atribuição de sentido se consegue que a aprendizagem de conteúdos específicos cumpra a função que lhe é determinada e que justifica a sua importância: contribuir para o crescimento pessoal dos alunos, favorecendo e promovendo o seu desenvolvimento e socialização. (ibid., p.14)
\end{abstract}

Com os dados coletados e atividades já desenvolvidas, a professora da classe, percebeu ser importante relacionar o conteúdo de ciências com as demais áreas do conhecimento. Foi possível, na disciplina de Português, desenvolver trabalhos com a leitura e a escrita, em matemática, a organização e interpretação de dados, contemplando assim, os conteúdos procedimentais. Em relação aos Conhecimentos Sociais, foi possível a Organização e leitura dos dados cartográficos sobre a merenda escolar e em Artes a Organização de painel. Ao valorizar as ideias dos alunos, na argumentação e nas suas posições diante das atividades desenvolvidas, os conteúdos atitudinais foram atingidos.

A fim de instigar os alunos, foram realizadas atividades com o objetivo de que pudessem compreender a importância de manter uma alimentação saudável para nosso organismo. Para tanto, propusemos aos alunos a criação de um joguinho, seguindo o modelo do Supertrunfo, uma vez que o jogo colabora com o aprendizado do aluno, fazendo com que ele assuma uma posição mais interativa com as propostas pedagógicas empregadas pelo professor. 
Optou-se, nesse encontro, por desenvolver com os alunos esse jogo, devido à percepção da docente de que, durante o recreio, a maioria dos educandos demonstrava enorme interesse pelos joguinhos de cartas. Assim, incorporamos o Supertrunfo, para a elaboração do conceito de nutrientes dos alimentos. O clássico jogo supertrunfo, que traz 32 cartas, fez sucesso nos anos 1980 e inicialmente tinha o tema sobre carros, sendo que os participantes deviam ganhar as cartas dos adversários com base nos atributos das que possuíam, como velocidade ou potência.

Atualmente há várias versões, e é possível utilizá-las no ambiente escolar. Além disso, o professor e os alunos podem preparar um jogo conforme o conteúdo que está sendo estudado, sendo que, quanto mais próximo do cotidiano, mais fácil será para compreender a lógica desse jogo. É importante deixar bem claro quais atributos que serão utilizados, as características da carta de um jogador com as do outro jogador, a característica que vai usar a cada rodada, pois se a carta de um jogador ganhar, ele fica com a carta do outro jogador; mas, se perder, ele fica com a sua e, no final, vence quem ganhar todas as cartas do jogo.

Nessa perspectiva de aprendizagem, percebe-se a necessidade de o professor assumir o ensino como uma ação e reação entre professor e aluno. O aprendizado não ocorre somente com o professor explicando o conteúdo em sua aula, mas em levar o aluno a pensar em caminhos para resolver determinadas situações-problema.

Ao serem questionados sobre o jogo utilizado, apenas dois alunos informaram que não o conheciam. Os demais tinham conhecimento do supertrunfo de carrinhos de corridas. Assim, com a mediação da professora, cada um foi organizando, conforme a informação, os alimentos que poderiam entrar no jogo.

Entre seus componentes, destacam-se a ação, o inter-relacionamento com os colegas e mesmo com o professor, além da curiosidade, da imaginação e da aceitação dos riscos inerentes a qualquer jogo, considerados dentro de uma ótica que estimule, acima de tudo, a aprendizagem.

Então, distribuímos o papel e as tesouras para que recortassem as cartas. Como cada aluno, queria utilizar um tamanho de carta, ficou então decidido que deveriam medir com a régua, sendo $5 \mathrm{~cm}$ de largura e $10 \mathrm{~cm}$ de comprimento. Em seguida, foram selecionados os carimbos de alimentos para que pudessem carimbar e colorir as figuras. Após terem colorido e recortado para colocar nas cartas, questionamos quais informações seriam interessantes para o jogo, sendo que a maioria dos alunos comentou que seria importante colocar os valores nutricionais dos alimentos naturais e industrializados.

Para o desenvolvimento dessa atividade utilizamos duas aulas, sendo que, em uma delas, fomos ao laboratório de informática para que todos os alunos pesquisassem as informações nutricionais de um alimento, na internet. Isso é mostrado na Tabela 1 a seguir:

Tabela 1 - Informação Nutricional - ABACAXI

\begin{tabular}{ll}
\hline & Medida: 1,3 fatia $=100 \mathrm{~g}$ \\
\hline Calorias & $48 \mathrm{cal}$ \\
\hline Carboidratos & $12,3 \mathrm{~g}$ \\
\hline Proteína & $0,9 \mathrm{~g}$ \\
\hline Água & $86,3 \mathrm{~g}$ \\
\hline Fibra alimentar & $1,0 \mathrm{~g}$ \\
\hline
\end{tabular}

Fonte: $<$ http://www.informacaonutricional.blog.br/abacaxi-tabela-valor/>

Quanto à leitura de tabelas, percebeu-se que os alunos conseguem fazer a leitura simples, porém de maneira satisfatória, pois, ao pesquisarem o valor nutricional das frutas, das verduras e das carnes, dentre outros ali- 
mentos, conseguiram identificar qual alimento é o mais calórico e qual é o menos calórico, pela comparação dos dados nutricionais. E, assim, ficou definido pela turma que as calorias dos alimentos deveriam constituir uma das regras do jogo. No QUADRO 3, pode -se verificar os desenhos utilizados para a montagem do jogo supertrunfo.

\section{Quadro 3 - Jogo Supertrunfo}

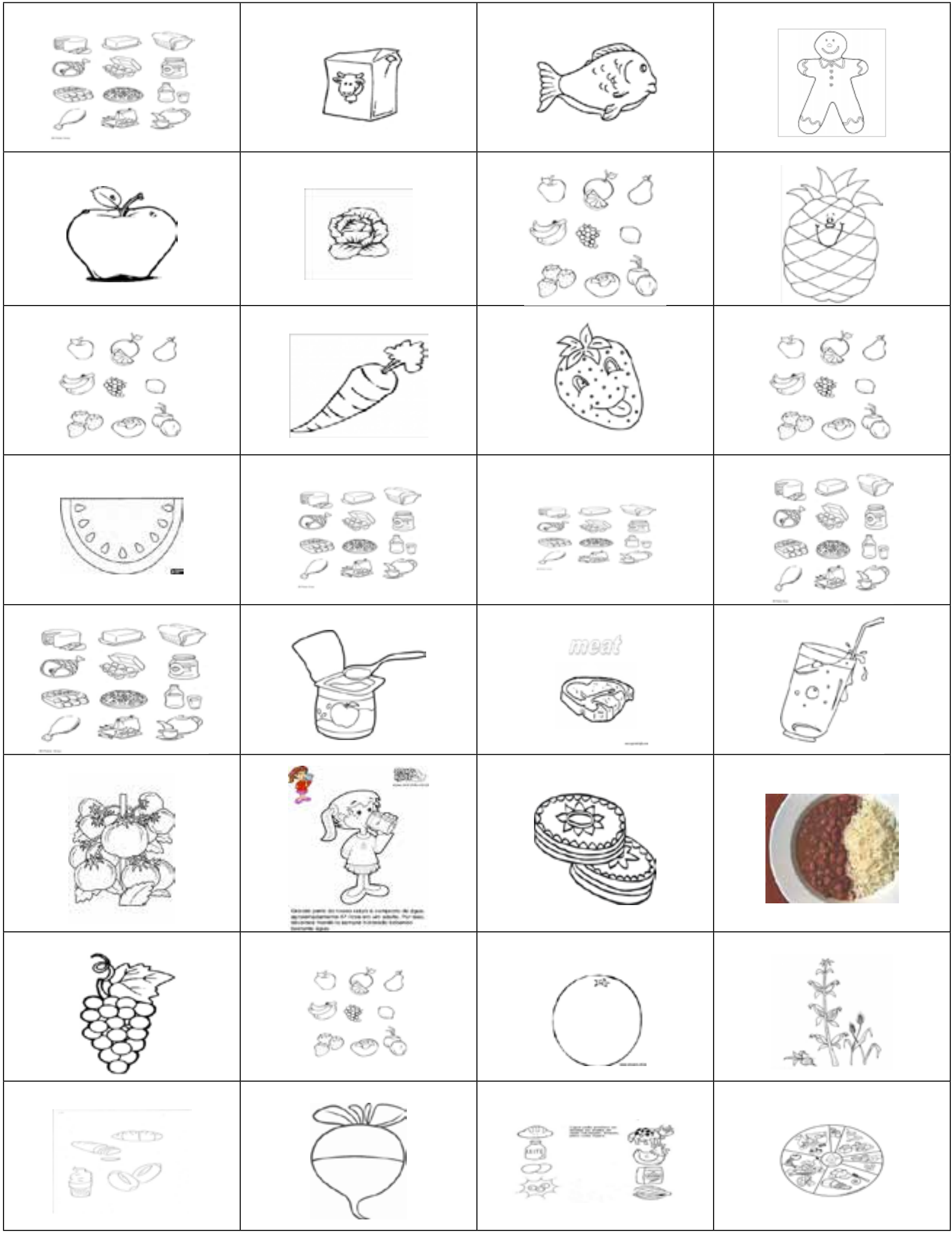

Fonte: Arquivo pessoal da autora 
Nessa atividade, considerou-se o momento da organização do conhecimento, explicado por Delizoicov, Angotti e Pernambuco (2002), como a sistematização dos dados coletados, sobre o valor nutricional dos alimentos. Em grupos, os alunos compartilharam as pesquisas realizadas sobre os alimentos industrializados, utilizando as tabelas de informações nutricionais dos alimentos. Foram também contemplados os conteúdos conceituais, pois segundo Coll (1992), a dimensão conceitual requer informação que consiste em dados ou fatos, para que os dados ou fatos adquiram significado, os alunos devem dispor de conceitos que lhes permitam interpretá-los. E, assim, ficou definido pela turma, que as calorias dos alimentos deveriam constituir uma das regras do jogo.

Para finalizar o conteúdo, os alunos desenvolveram o jogo supertrunfo com figuras de alimentos naturais e industrializados, conforme a FIGURA 4.

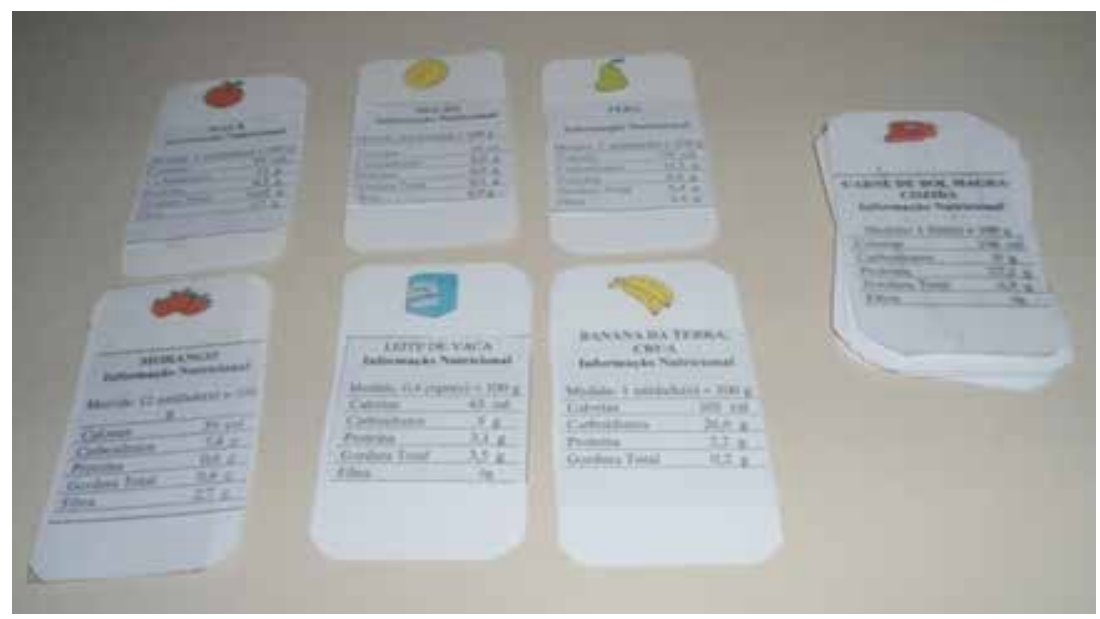

Figura 4 - Jogo supertrunfo Fonte: Arquivo pessoal da autora.

Com o jogo pronto, é hora de jogar, e o importante é que os alunos entenderam os critérios para determinar qual alimento é mais calórico quando fazem a comparação das cartas. Na verdade, cada carta envolve várias informações sobre determinado alimento e vários alimentos estão em jogo, o que exige de cada jogador que não só olhe o detalhe de uma carta, mas que considere o conjunto das cartas, o que certamente força a ampliação do horizonte de observação da chamada realidade imediata² .

A reação dos alunos na realização dessa atividade foi de alegria e de prazer, além do interesse pelo material do jogo, pelas regras e pelo desafio proposto, envolvendo-os e os estimulando à ação. Segundo, Azevedo (1993), o jogo não é um recurso para tornar as aulas mais agradáveis, mas uma ponte para o conhecimento.

Ao final das atividades propostas para o jogo supertrunfo, pôde-se constatar que os aspectos conceituais foram contemplados na pesquisa sobre as informações nutricionais de cada alimento, ao analisar e comparar qual alimento é mais calórico ou menos calórico. Como se sabe, as condições necessárias para a aprendizagem dos conteúdos conceituais demandam atividades que, além de considerarem os conhecimentos prévios dos alunos, promovem a formulação de novos conceitos.

Assim, ao favorecer atividades em que os alunos são estimulados a refletir com certos parâmetros e a analisar os dados apresentados, como ocorreu nessa atividade, o professor está provendo a aprendizagem de

2 A percepção da realidade imediata advém do reconhecimento de que o conhecimento matemático propicia respostas prático-utilitárias para atividades da vida cotidiana, resultando na compreensão do seu significado no momento em que está sendo efetivada, evidenciando o imediatismo da aprendizagem (GIARDINETTO, 1997). 
procedimentos. E, ainda, pelo fato de valorizar o posicionamento dos alunos sobre as regras do jogo, em que ficou definido que seria pelo maior valor calórico do alimento, foi um dos momentos em que se contemplou a aprendizagem referente aos conteúdos atitudinais.

Em resumo, com as atividades desenvolvidas, foram contemplados os conteúdos conceituais, tendo em vista que foi possível os alunos perceberem a importância de cada alimento para a saúde de cada um. Também se contemplou a aprendizagem dos conteúdos atitudinais, o que pôde ser percebido percebe-se nas falas dos alunos. E nos conteúdos de procedimentos, que segundo Coll (1998), são aqueles que fazem referência ao saber fazer, isto é, as técnicas de estudo, os métodos investigativos, às estratégias e habilidades que possibilitam a execução de tarefas ou de ações relacionadas à aprendizagem o que ficou claro na a organização e elaboração do livrinho, envolvendo leitura e escrita.

\section{CONCLUSÃO}

O ensino de Ciências, desde os primeiros anos do Ensino Fundamental, na educação escolar atual filia-se à proposta de contribuir para uma aprendizagem contextualizada, no sentido de propiciar ao aluno a formação de sua consciência crítica e interdisciplinar.

Os temas geradores, incorporados à prática docente, permitem que haja o estabelecimento de uma relação entre os conteúdos da disciplina com a realidade do educando, aliando a teoria à prática. Em consequência disso, "exige-se" do aluno a participação mais ativa, seja no entendimento da situação enfocada, seja na assimilação do saber científico, resultando em uma aprendizagem adequada à sua condição de cidadania.

O docente, por sua vez, ao utilizar os temas geradores, configura sua condição de mediador do processo de ensino, estabelecendo um diálogo consistente com os educandos, possibilitando que sua prática pedagógica possa atender às expectativas dos envolvidos nesse processo, que vai desde o educando no espaço escolar à comunidade como um todo.

\section{REFERÊNCIAS}

AZEVEDO, Maria Verônica Rezende de. Jogando e construindo a matemática: a influência dos jogos e materiais pedagógicos na construção dos conceitos em matemática. São Paulo: Editora Unidas, 1993.

BRASIL. Secretaria de Educação Fundamental. Parâmetros Curriculares Nacionais: Ciências Naturais. Brasília: MEC SEF, 1997.

Lei n. 9.394, de 20 de dezembro de 1996. Estabelece as diretrizes e bases da educação nacional. Brasília: Diário Oficial, 1996.

CARVALHO, Anna Maria de Pessoa et alii. Ciências no ensino fundamental: o conhecimento físico. São Paulo: Scipione, 2007.

COLL, C. et al. Os Conteúdos na Reforma: ensino e aprendizagem de conceitos, procedimentos e atitudes. Porto Alegre: Artmed. 1998.

DELIZOICOV, Demétrio; ANGOTTI, José André. Metodologia do ensino de Ciências. São Paulo:Cortez,2000.

DELIZOICOV, Demétrio; ANGOTTI, José André. Metodologia do ensino de ciências. São Paulo: Cortez, 2000 (Coleção Magistério - $2^{\circ}$ grau - Série Formação do Professor). 
DELIZOICOV, Demétrio; ANGOTTI, José André; PERNAMBUCO, Marta Maria. Ensino de ciências: fundamentos e métodos. São Paulo: Cortez, 2002.

Ensino de ciências: fundamentos e métodos. 4.ed.São Paulo: Cortez, 2011.

FREIRE, Paulo. Pedagogia da autonomia: saberes necessários à prática educativa. 31. ed. São Paulo: Paz e Terra, 1999.

Pedagogia do oprimido. 42 ed. São Paulo: Paz e Terra, 2005.

GADOTTI, Moacir. Escola cidadã. 11. ed. São Paulo: Cortez, 2006.

GASPARIN, João Luiz. A problematização como desafio metodológico do ensino superior. In: Teoria e Prática da Educação - Revista de Departamento de Teoria e Prática da Educação, vol. 1, nº 1, set. 1998.

LÜCK, Heloisa. Pedagogia interdisciplinar: fundamentos teórico-metodológicos. 4. ed. Petrópolis, RJ: Vozes, 1998.

NIGRO, Rogério G.; CAMPOS, Maria Cristina da C. Ciências - aprendendo sempre. 1. ed. São Paulo: Ática, 2009.

PILETTI, Nelson. Psicologia educacional. 17 ed. São Paulo: Ática, 2006.

SOARES, Maria de Fátima Cardoso. A docência nas séries iniciais do ensino fundamental: reflexões sobre a mobilização do saber experimental. Disponível em: <http://www.ufpi.edu.br/subsiteFiles/ppged/arquivos/files/ eventos/2006. gt3/GT3_2006_01.PDF>. Acesso em: 20 jul. 2012.

TAVARES, R. Aprendizagem significativa e o ensino de ciências. Disponível em: <http://www.fisica.ufpb. br/ romero/pdf/ANPED-28.pdf>. Acesso em: 20 fev. 2011.

ZABALA, Antonio. Como trabalhar os conteúdos procedimentais em aula. Editora Artmed. 1999. $2^{\mathrm{a}}$ ed. Porto Alegre. 